\section{THE CARBON FACTOR IN THE GENESIS} OF GOUT.

To the Editors of 'THE LANCET.

SIrS,-In ThE LanceT of Feb. 11th (p. 348) Dr. D. F. Shearer contributed an article entitled "Carbonic Acid as a Factor in the Genesis of the Gouty State." This article is noteworthy in that it directs attention-for the first time, so far as I know-to a retardation of carbonaceous excretion as the fundamental factor in gout. The writer argues that in the gouty the intake and absorption of carbonaceous material are excessive as regards the amount of physical exercise; that consequently the arterial blood is flooded with carbonic acid; that this excess of carbonic acid is responsible for the retention in the blood of uric acid which is known to occur in gout; and that the salutary influence of physical exercise in the gouty depends upon the increased exhalation of carbonic acid from the blood. A weak point in this hypothesis is that exercise increases, not only the exhalation, but the production, of carbonic acid.

Further than this, the argument rests upon the assumption -widespread but premature in my opinion-that carbonaceous material absorbed from the alimentary canal is of necessity katabolised or anabolised. Normally the blood is relieved of its carbonaceous material mainly by the capacities of the nitrogenous tissues for katabolism and anabolism; but we have no warrant for assuming that these capacities are invariably adequate for the task. Indeed, it seems a larger assumption to postulate an invariable adequacy than an occasional inadequacy.

Now an inadequacy of carbonaceous metabolism, even thongh slight, would lead to an accumulation of carbonaceous material of some kind in the blood. And if this be granted a large number of observations (experimental and others) could be adduced to show that such an accumulation leads to deficient renal excretion of uric acid. The result would be the progressively increasing uricæmia which is known to antecede the paroxysm of articular gout. Such would eventually involve extravascular deposition of a portion of the uratic load; and should this occur, as commonly happens, in some structure such as a joint which is capable of responding by acute inflammation to the irritation of the urate then we should have a paroxysm of acute articular gout. On this view the mechanism and influence, not less than the causation, of acute gout become clear. Acute arthritis involves pyrexia; pyrexia increases the rate of combustion and so disperses the carbonaceous accumulation; the dispersion of the carbonaceous accumulation releases the uric acid accumulation and permits of free renal elimination ; through renal elimination the blood recovers its solvent power and reabsorbs the extravascular deposits of uric acid. Thus is established convalescence not only from the arthritis but also from the condition of depraved general health which so commonly antecedes the arthritis and which is concurrent with the double progressive accumulation referred to. As Mead long ago said, "Gout is the cure of gout."

I believe that a progressive carbonaceous accumulation is a common humoral factor of disease and leads under varying conditions to various paroxysmal affections (amongst them acute articular gout), most of which result in relief from the carbonaceous accumulation.

Feb. 27th, 1905. I am, Sirs, yours faithfully, Francis Hare.

\section{OLD EPSOMIANS AND THE JUBILEE OF EPSOM COLLEGE. \\ To the Editors of THE LANCET.}

SIRs,-May I through your columns make known to old Epsomians generally (a very large percentage of whom enter the medical profession) that the Hpsomian Club, in conjunction with the present head master, Dr. Hart SmithPearse, are arranging to commemorate the jubilee year of the school (1905) by publishing a register of old boys and their various professions, distinctions, \&c., together with a brief sketch of the history of the college since 1855 and other items of interest?

Some dozen or so of us have undertaken the task of collecting the necessary statistics and circulars have been sent to all those whose addresses we can find. There are many hundreds of old boys, especially those who joined the
College in its earlier years, whom we cannot trace and therefore I venture to ask, through your columns, any old Epsomians who have not received any intimation and who know the addresses of any old school fellows, especially those who have not entered the medical profession, to be kind enough to send me a postcard so that we may get into communication with them.

I am, Sirs, yours faithfully,

4, Adam-street, Adelphi, London, W.C., Percival Turner. March 13th, 1905.

\section{THE MEDICO-PSYCHOLOGICAL ASSOCIA- TION OF GREAT BRITAIN AND IRELAND.}

To the Editors of THE LANCET.

Sins, - From personal knowledge of the experience and the exceptional ability of the reporter of the Medico-Psychological Association quarterly meeting at York on Feb. 23rd last I authorised him to send a report to your columns. He now writes to me expressing his regret that the substitution of the word "two" for "three" should have occurred as a purely accidental error in transcribing. I desire to be associated with his regret.

I am, Sirs, yours faithfully,

ROBERT JONES,

Honorary General Secretary of the Medico-Psycho-

March 14th, $1905 . \quad$ logical Association of Great

\section{SHIFTING DULNESS IN PLEURAL EFFUSION.}

To the Editors of THE LANCET.

SIRs,-Mr. Rickman J. Godlee's paper on Shifting Dulness, which appeared in THE LANCET of Feb. 25th, p. 480, though written primarily from the surgical point of view, invites comment from a physician. Mr. Godlee implies, and in your leading article upon his paper in the issue of March 4th you definitely assert, that "it is generally taught that the dulness due to a pleuritic effusion or to an empyema shifts with position under the influence of gravity." I should not have thought this to be the case but, on the contrary, I should have supposed it to be now generally accepted that the level of dulness in simple pleural effusion, whether serous or purulent, did not readily shift with position. I certainly have taught this for many years and in my book on "Diseases of the Respiratory Organs," p. 659, I write as follows :-

Alteration of percussion lines with position.-In cases of hydropneumothorax, i.e., where air and fluid are present together in the pleura, it is very easy to make out the change of level, for this takes place quickly as the patient changes his position from the recumbent to the sitting posture ; but it is not by any means so easy to demonstrate this change when fluid alone exists in the pleura. A change indeed does take place, but in most cases only slowly. The explanaindeed does take place, but in most cases only slowly. The explanafion is to be found in the fact already mentioned-viz., that as fluid forms, although the lung no doubt undergoes general shrinkage from its own elasticity, still the collapse is most marked and may be com plete in those portions of the lung which are immediately adjacent to the fluid, while the rest seems to be pro tanto dilated. In this way the fluid is to some extent held up, as it were, against the action of gravity, or, at any rate, the lung will not float as readily or change its
position as easily as we might expect.

I would add that if the dulness does not shift in front or in the axilla it is still less likely to do so behind, for it is at the base posteriorly that the collapse of the lungs is most marked. If these facts are not yet generally recognised they have, at any rate, been long enough known, as the following quotation from Fagge ${ }^{1}$ shows:

A circumstance which has long attracted the attention of clinical physicians is that temporary changes of posture of the patient often fail to alter the position of the liquid within the chest so far as one can test by percussion.

The answers sometimes given by students in examination, if they may be taken as any indication of the views of their teachers, seem to justify the conclusion drawn by Mr. Godlee that the teaching on this point is in some quarters not sound. The fact is of so much importance and ignorance of it may so easily lead to errors in diagnosis that $\mathrm{Mr}$. Godlee has done good service in drawing attention afresh to it.

The upper borders of the liver and the heart as determined 
by percussion remain the same both in the erect and recumbent position. No doubt this is in part due to the comparative flatness of the arch of the diaphragm in front, but it is chiefly the effect of the action of the abdominal muscles which in the erect position contract and thus support the weight of the liver and the heart and prevent them from falling. Where the abdominal muscles are greatly relaxed or very weak it is probable that these organs may fall in the erect position and the upper limit then descend.

It is, as Mr. Godlee says, useless to percuss out the abdominal viscera when the patient is standing up, but I do not agree with the explanation which he gives-viz., that there is in the young and healthy adult not much gas in the small intestines and only a moderate amount in the stomach and large intestine. "The true explanation is to be also found, I believe, in the contraction of the abdominal muscles, which is of itself sufficient to give an impaired or even a dull note. I remember an excellent illustration of this being given by an acrobat who exhibited himself in the theatre at St. Bartholomew's Hospital. He was able to dislocate most of his joints by muscular action and could wriggle through a hoop only just large enough to go over his head. He was able also to produce a phantom tumour in the abdomen as large as his head. Percussion over this was quite dull and the dulness was evidently due to contraction of the abdominal muscles. When the abdominal muscles are large and well nourished, as in the young healthy adult, their contraction in the erect position would rob abdominal percussion of any value. In overfed dyspeptic persons with pendulous belly and illnourished muscles the difficulties of percussion in the upright position though decreased by the want of tone in the muscles would be increased by the amount of fat in the abdominal walls. So that in any case abdominal percussion in the erect position would be misleading.

I am, Sirs, yours faithfully,

Wimpole-street, W., March 6th, 1905. SAMUEL WEST.

\section{THE GOUTY DIATHESIS.}

\section{To the Editors of THE LANCET.}

SIRs,-As it appears from Dr. S. A. Arany's letter published in THE LANCE' of March 4th that he has misunderstood the aim of the experimental investigations recorded in my paper in your issue of Feb. 11th, and also my estimate of the significance of their results, perhaps you will kindly allow me to make these points clear. It is generally admitted that an excessive meat dietary is prejudicial to gouty individuals, the reason usually assigned being the large amount of uric-acid-forming bodies in this diet. As a result of a long series of laboratory investigations I was led to conclude that uric acid does not play the important etiological rôle in the production of gout that is commonly supposed and in this connexion it is of interest to note that this teaching of the laboratory is in harmony with the views expressed by some leading clinicians of wide experience in this disease. In a recent paper ${ }^{1}$ I submitted a summary of the facts obtained in these investigations and I suggested that the present position of our knowledge of gout made it advisable to prosecute inquiry along the following lines: (1) to ascertain the effects of a special dietary-e.g., an excessive meat diet-on the economy; and (2) to test the validity of the view that there is an infective element in the disease. In pursuance of this inquiry I fed a number of fowls on a diet of meat and water. Fowls were selected as being subjects relatively prone to over-production of uric acid in the tissues. I later made a series of similar observations on rats, whose normal diet more closely resembles that of the human subject. In neither series was there any deposit of urate of soda; in both very striking changes were induced in the thyroid glands. Dr. Arany states that this result proves nothing regarding gout. I quite agree with him. My point is that the facts are most suggestive and it appears to me that they justify the suggestion that in people who persistently take an ex cessive amount of meat or whose forbears have over-indulged in this direction there may be present a condition of thyroid gland which is different from that of healthy individuals and, further, that this difference may have something to do with the gouty diathesis. Dr. Arany lays stress on the facts that gout is found in subjects who have never been large consumers of meat and may even be met with in patients who are practically abstainers from a meat diet. These may be regarded as well-established facts in the disease but I submit that a deeper insight into the significance of these facts may lead to their being correctly regarded as important evidence in favour of my theory. No definite statement on this point can be made until we ascertain the condition of the thyroid and the forms of its functional activity in the cases referred to by Dr. Arany.

Your correspondent states that in a series of almost 400 cases of gout he "did not observe in a single case any symptoms which could have related to changes in the thyroid gland." This statement implies two assumptions which call for comment. It presumes a precise knowledge of the functions of the thyroid gland and also a comprehensive grasp of the changes induced in the economy by a diminished secretion (hypothyroidism), excessive secretion (hyperthyroidism), and perverted secretion of the gland. With regard to the first assumption, I would point out that recent works (Jeandelize, Swale Vincent and Jolly, and others) have shown that our knowledge of the physiology of the gland is very incomplete. With regard to the second assumption, it is probably not too much to say that all clinicians who have devoted special attention to the subject of the thyroid gland in its clinical and therapeutic aspects are of opinion that a knowledge of the changes induced in the system by alterations in the character of the thyroid secretion still remains one of the most important desiderata in our medical knowledge. In these circumstances one is perhaps justified in hesitating to attach much scientific value to Dr. Arany's pronouncement on the results of his clinical experience regarding a relation between gout and the thyroid gland, and it may not be unreasonable to hope that a record of fresh and important facts, which show the possibility of such a relation, may lead clinicians who have shared his experience to extend the area of their observation, and closely to scrutinise the facts that lie within their purview, in order to obtain positive evidence for or against the existence of the suggested relation.

I am, Sirs, yours faithfully,

Edinburgh, March 6th, 1905.

Chalmers Watson.

\section{THE INTRUSION OF THE LAYMAN INTO MEDICAL PRACTICE.}

To the Editors of $\mathrm{THE} \mathrm{LANCET}$.

SIRs,-May I be allowed to draw attention to some points raised by the letter in The LANCET of March 4th from Messrs. Allen and Hanbury? The particular case mentioned can no doubt be dealt with by the gentleman whose letter called forth their reply but in the latter half of their letter Messrs. Allen and Hanbury write as if thereby they dispose of the whole question. I venture to think that there is more to be said. No one can blame Messrs. Allen and Hanbury for opening "a department of business" at the request of leading members of the medical profession. That they should carry it on-with a costly plant requiring constant expense to keep it up to date and an assistant paid we hope an adequate living wage, and all this at "an entirely insignificant profit"-seems worthy of commendation from all but shareholders. This "department of business" is described as an endeavour to assist the profession in "mere mechanical and subsidiary matters." It is admitted that it includes not only the taking of $\mathrm{x}$ ray negatives but also exposures for treatment. The assistant who does the work has no medical qualification. The necessity for medical training in the making, and especially in the interpretation, of $\mathrm{x}$ ray negatives is obvious enough to all who are conversant with the subject. The therapeutic use of $x$ rays should certainly be in the hands of medical men who have given time and study to the subject. It is beside the mark to say " under the direction of the medical man," for unless himself well versed in the detail of the work he is entirely in the hands of the person to whom he intrusts it. As to the "presence of " the same, it would be interesting to know how often the medical man attends the numerous sittings necessary. Then as to the establishment of such a "department of business" by a commercial firm. Why should it be called for at all-even if conducted on the almost philanthropic lines of Messrs. Allen and Hanbury? It is open to the profession, as they kindly point out, to "take patients to professional brethren who practise radiography," "but 